\title{
Ocena odporności na korozję wysokotemperaturową złączy paneli ścian szczelnych z nierdzewnej stali austenitycznej spawanych hybrydowo
}

\author{
Evaluation of high temperature corrosion resistance \\ of hybrid welded membrane walls panels joints \\ of austenitic stainless steel
}

\section{Streszczenie}

Wzrastające zapotrzebowanie na energię elektryczną oraz wymagania unijne, dotyczące zwiększenia sprawności cieplnej bloków energetycznych i ograniczenia emisji szkodliwych gazów do atmosfery, stwarzają konieczność modernizacji przemysłu energetycznego. Jednym ze sposobów pozwalającym sprostać tym wymaganiom jest podniesienie parametrów pary, co wpływa na wzrost sprawności cieplnej. Jednak uzyskanie sprawności netto powyżej $50 \%$ jest zależne od zastosowania nowych technologii oraz materiałów o większej żaroodporności i żarowytrzymałości niż dotychczas stosowane. Artykuł przedstawia wyniki badań odporności na korozję wysokotemperaturową złączy spawanych metodą hybrydową (laser + MAG) paneli ścian szczelnych ze stali nierdzewnej typu 304. Próbki poddano działaniu atmosfery o składzie $\mathrm{N}_{2}+9 \% \mathrm{O}_{2}+0,08 \% \mathrm{SO}_{2}$ w temperaturze $700{ }^{\circ} \mathrm{C}$ przez czas 1000 godzin. Jako miarę odporności na korozję wysokotemperaturową przyjęto zmiany masy próbek. Utworzoną na powierzchni warstwę produktów korozji obserwowano za pomocą elektronowej mikroskopii skaningowej. Uzupełnieniem badań była mikroanaliza składu chemicznego (EDS) oraz składu fazowego (XRD). Podczas badań ujawniono utworzenie na powierzchni materiału warstwy zgorzeliny, zbudowanej głównie $\mathrm{z} \mathrm{Cr}_{2} \mathrm{O}_{3}$ i $\mathrm{Fe}_{3} \mathrm{O}_{4}$.

Słowa kluczowe: korozja wysokotemperaturowa; ściany szczelne; stal nierdzewna austenityczna; spawanie hybrydowe laser + MAG

\begin{abstract}
The growing demands for electricity and UE requirements, regarding the increase in thermal efficiency of power boilers and the reduction of pollution emission to the atmosphere, create a need to modernize the power industry. Raising the parameters of the steam, which increases the thermal efficiency, is one of the ways to meet this requirements. However, achieving a net efficiency of approx. $50 \%$ depends on the use of new manufacturing technologies and materials with higher creep resistance than previously used. This article presents the results of high-temperature corrosion resistance test of hybrid welded joints (laser + MAG) of austenitic stainless steel grade 304 used for membrane wall panels. The specimens were placed in an oven in an atmosphere with the composition: $\mathrm{N}_{2}+9 \% \mathrm{O}_{2}+0.08 \% \mathrm{SO}_{2}$ at a temperature of $700{ }^{\circ} \mathrm{C}$ and an exposure time of 1000 hours. As a measure of high-temperature corrosion resistance, changes of the mass were adopted. In order to evaluate the oxide layer formed on the surface of the material, the specimens were observed on a scanning electron microscope. The supplement of the research was the chemical (EDS) and phase (XRD) composition analysis. The results confirmed the presence of a layer consisting mainly of $\mathrm{Cr}_{2} \mathrm{O}_{3}$ and $\mathrm{Fe}_{3} \mathrm{O}_{4}$.
\end{abstract}

Keywords: high-temperature corrosion; membrane panels; stainless steel; hybrid welding laser + MAG

\section{Wprowadzenie}

Korozja wysokotemperaturowa występuje najczęściej w kotłach o wysokich parametrach pary, atakując głównie nagrzane do wysokiej temperatury elementy konstrukcji kotłów. Jest to chemiczny proces utleniania metali w wysokiej temperaturze, w atmosferze spalin lub środowiskach zawierających siarkę lub siarkowodór. Specyfikacja korozji wysokotemperaturowej polega na tym, że na powierzchni metalu nie powstaje jednorodna, pasywna warstwa tlenków,

mgr inż. Anna Kamela; dr hab. inż. Janusz Adamiec, prof. PŚı - Politechnika Śląska.

Autor korespondencyjny/Corresponding author: anna.kamela@polsl.pl 
tak jak to ma miejsce w warunkach normalnego utleniania. Dla wystąpienia tego typu korozji oprócz odpowiedniego składu chemicznego spalin potrzebna jest wysoka temperatura. Przy niedoborze tlenu w palenisku, siarka, chlor oraz fluor reagują z tlenem tworzącym ochronną warstwę tlenków na powierzchni rur. Następnie reagują z żelazem i powodują szybki ubytek grubości ścianki [1].

Korozja wysokotemperaturowa objawia się zniszczeniem materiału i obniżeniem jego właściwości wytrzymałościowych. Jest częstą przyczyną awarii związanych z nieszczelnościami ekranów oraz koniecznością ich wymiany, co prowadzi do poniesienia kosztów związanych z wyłączeniem kotła [2,3]. Zapewnienie odpowiedniej odporności na działanie agresywnego środowiska korozyjnego odbywa się poprzez modyfikację struktury i właściwości stali odpowiednimi pierwiastkami stopowymi. Oprócz odpowiednich właściwości mechanicznych, od materiałów wymaga się również odporności na szoki termiczne, wysokotemperaturowej odporności korozyjnej w złożonych oraz agresywnych atmosferach zawierających m.in. związki siarki, tlenu czy parę wodną [4].

Podstawową grupą stali odpornych na korozję są wysokostopowe nierdzewne stale austenityczne. Dodatki stopowe takie jak N, Mo, Si, Cu, Ti i Nb oraz obniżenie zawartości C powodują wzrost wytrzymałości na pełzanie, podwyższenie odporności korozyjnej oraz odporności na działanie kwasów i zasad. Jest to związane z tworzeniem się na powierzchni materiałów pasywnych warstw tlenków, zawierających $\mathrm{Cr}_{2} \mathrm{O}_{3}$, $\mathrm{Fe}_{3} \mathrm{O}_{4}$ [2]. Wraz ze wzrostem zawartości chromu w stalach, paraboliczny przebieg utleniania ulega wydłużeniu na skutek zmian morfologii tlenku, począwszy od $\mathrm{Fe}_{2} \mathrm{O}_{3} / \mathrm{Fe}_{3} \mathrm{O}_{4}$ przez $\mathrm{Fe}_{3} \mathrm{O}_{4} /(\mathrm{Fe}, \mathrm{Cr})_{3} \mathrm{O}_{4}$ oraz $\mathrm{Fe}_{3} \mathrm{O}_{4} /(\mathrm{Fe}, \mathrm{Cr})_{3} \mathrm{O}_{4} / \mathrm{Cr}_{2} \mathrm{O}_{3}$ do warstwy czystego $\mathrm{Cr}_{2} \mathrm{O}_{3}$ (rys. 1). Kolejne zmiany morfologii przyczyniają się do coraz lepszej ochrony powierzchni $[5,6]$.

Cykliczna praca bloków energetycznych sprzyja rozwojowi procesów niszczenia korozyjnego. Dlatego produkty korozji cechują się budową warstwową o zróżnicowanych właściwościach takich jak porowatość, przyczepność do podłoża. Skutkiem jest okresowe odpadanie warstw tlenków, co obok skoków temperatury wpływa na kinetykę utleniania. Taki proces prowadzi również do ubytku grubości oraz wzrostu naprężeń w materiale rury.

Z jednej strony mechanizm narastania warstw tlenków na powierzchni rur jest zjawiskiem pożądanym, zapewniającym ochronę rury przed dalszą korozją. Jednak z drugiej, na skutek wzrostu grubości warstwy tlenkowej, pogarsza wymianę ciepła. Skutkuje to zwiększaniem temperatury ścianki, co sprzyja degradacji struktury $[2,6]$.

\section{Cel badań}

Celem badań odporności na korozję wysokotemperaturową było określenie odporności złączy spawanych na działanie wysokiej temperatury oraz agresywnego środowiska spalin. a)

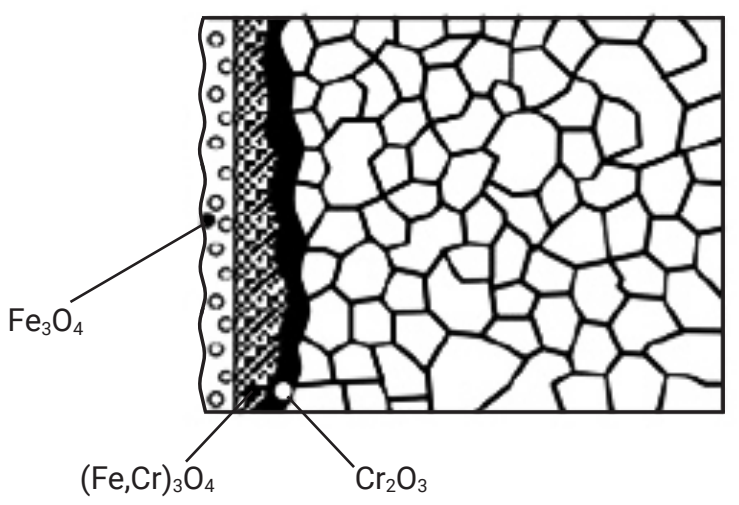

b)

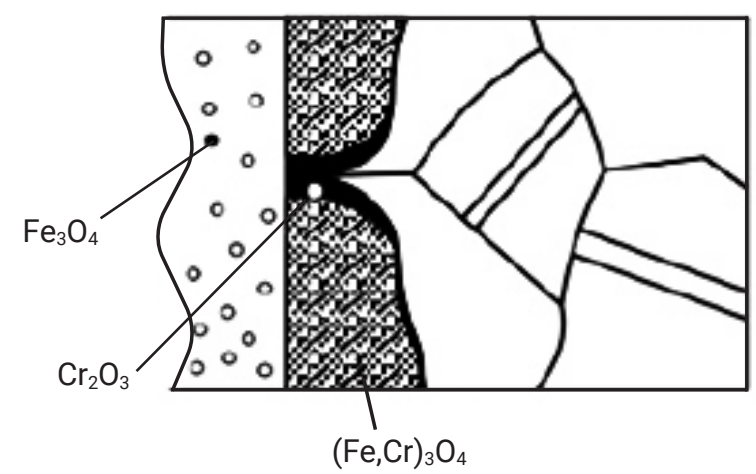

Rys. 1. Schemat tworzenia się tlenków na powierzchni stali austenitycznej w podwyższonej temperaturze o strukturze: a) drobnoziarnistej, b) gruboziarnistej [7]

Fig. 1. Scheme of formation of oxides on the surface of austenitic steel at elevated temperature of the structure: a) fine-grained, b) coarse-grained [7]

\section{Materiał do badań}

Badany element paneli ścian szczelnych został wykonany ze stali austenitycznej typu 304 (X5CrNi18-10; 1.4301 wg EN 10088-1) o składzie chemicznym podanym w tablicy I. Element składał się z rury o wymiarach $\varnothing 38 \mathrm{~mm}$ x 3,6 mm połączonej z płaskownikiem $15 \mathrm{~mm}$ x $5 \mathrm{~mm}$ (rys. 2) z zastosowaniem spawania hybrydowego laser + MAG. Długość złącza spawanego wyniosła $1 \mathrm{~m}$. Proces spawania został wykonany przez firmę Energoinstal S.A. Prędkość spawania wynosiła $1 \mathrm{~m} / \mathrm{min}$, moc wiązki laserowej 2,25 kW, system ogniskowania wiązki: optyczny - podwójna ogniskowa $268 \div 273 \mathrm{~mm}$.

\section{Metodyka i wyniki badań}

Badania zostały wykonane na stanowisku, którego schemat blokowy przedstawiono na rysunku 3. Jako atmosferę gazów zastosowano mieszaninę o składzie $\mathrm{N}_{2}+9 \% \mathrm{O}_{2}+0,08 \% \mathrm{SO}_{2}$.

Tablica I. Skład chemiczny stali 304 (\% mas.) na podstawie atestów materiałowych typu 3.1, zgodnych z PN-EN 10204

Table I. Chemical composition of 304 stainless steel (wt \%) on the basis of 3.1 material certificates, according to PN-EN 10204

\begin{tabular}{|c|c|c|c|c|c|c|c|c|c|}
\hline & $\mathbf{C}$ & $\mathbf{M n}$ & $\mathbf{P}$ & $\mathbf{S}$ & $\mathbf{S i}$ & $\mathbf{C r}$ & $\mathbf{N i}$ & $\mathbf{N}$ & $\mathbf{F e}$ \\
\hline EN 10088-1 & $\max 0,070$ & $\max 2,00$ & $\max 0,040$ & $\max 0,015$ & $\max 1,00$ & $17,50 \div 19,50$ & $8,00 \div 10,50$ & max 0,110 & osnowa \\
\hline Rura & 0,021 & 1,64 & 0,038 & 0,004 & 0,50 & 18,68 & 9,00 & 0,032 & osnowa \\
\hline Płaskownik & 0,024 & 1,81 & 0,030 & $<0,001$ & 0,32 & 18,10 & 8,00 & 0,044 & osnowa \\
\hline
\end{tabular}



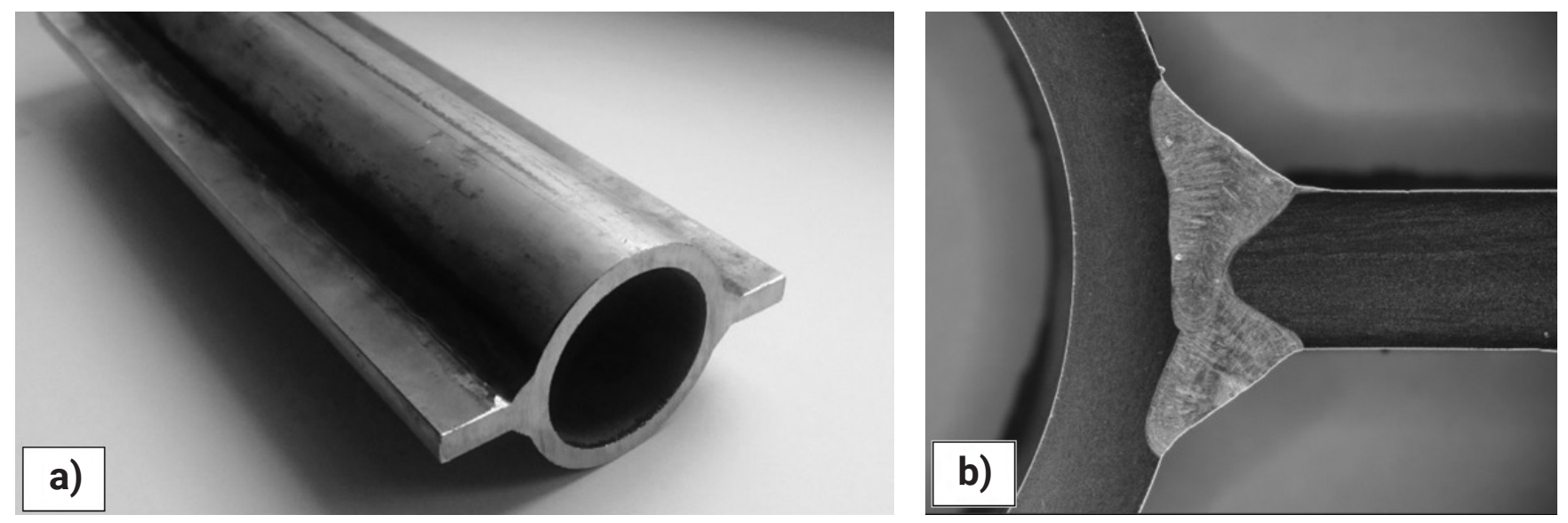

Rys. 2. Materiał do badań: a) fragment paneli ścian szczelnych, b) makrostruktura złącza

Fig. 2. Material to investigation: a) a part of membrane panel, b) macrostructure of the joint

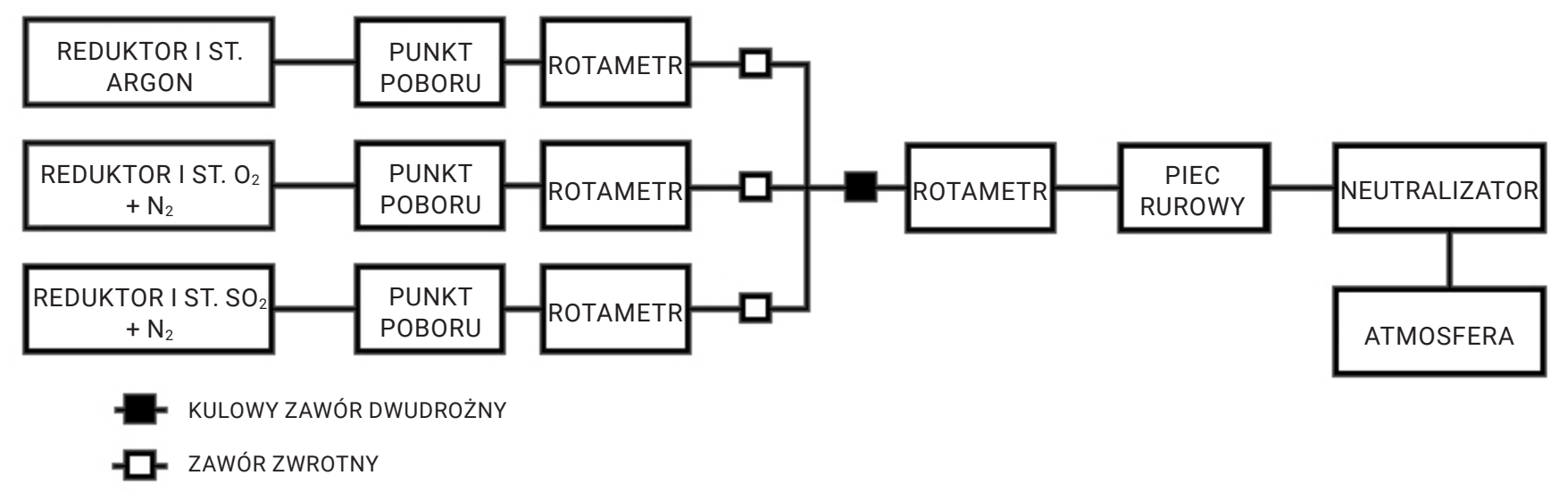

Rys. 3. Schemat stanowiska do badania odporności na korozję wysokotemperaturową

Fig. 3. Diagram of the stand for testing high-temperature corrosion resistance

Próbki umieszczono w komorze pieca nagrzanej do $700{ }^{\circ} \mathrm{C}$ na czas 1000 h. Za miarę odporności na korozję wysokotemperaturową złączy przyjęto zmiany masy $(\Delta \mathrm{m})$ próbek w trakcie badań. Pomiar przyrostu masy przeprowadzano co 250 h (pięć pomiarów). Przykładową próbkę po badaniu oraz kinetykę procesu utleniania pokazano na rysunku 4.

W celu oceny warstwy tlenków utworzonej na powierzchni materiału, próbki poddano obserwacji na elektronowym mikroskopie skaningowym (rys. 5). Za pomocą spektrometru EDS wykonano powierzchniowy rozkład pierwiastków wchodzących w skład warstwy korozyjnej (rys. 6). Wyniki mikroanalizy składu chemicznego warstwy produktów korozji oraz analizy składu fazowego przedstawiono na rysunku 7.
Analiza zmian masy próbek wskazuje, że przyrost produktów korozji przebiega zgodnie z liniowym prawem utleniania (rys. 4). Szybkość procesu korozji wyniosła ok. 0,2 mg/100 h. Mikroanaliza składu chemicznego produktów korozji wykazała zwiększoną zawartość chromu i żelaza. Wyniki identyfikacji składu fazowego potwierdziły obecność pasywnej warstwy, składającej się głównie $\mathrm{z} \mathrm{Cr}_{2} \mathrm{O}_{3}$ oraz $\mathrm{Fe}_{3} \mathrm{O}_{4}$ (rys. 7). Stwierdzono skłonność do segregacji tlenków chromu i tlenków żelaza w utworzonej warstwie. $\mathrm{Cr}_{2} \mathrm{O}_{3}$ głównie rozmieszczony jest po wewnętrznej stronie warstwy, od strony materiału rodzimego, podczas gdy największa ilość $\mathrm{Fe}_{2} \mathrm{O}_{3}$ znajduje się w warstwie wierzchniej (rys. 6). Utworzona warstwa wykazuje w obszarze spoiny skłonność do rozwarstwiania (rys. 5).
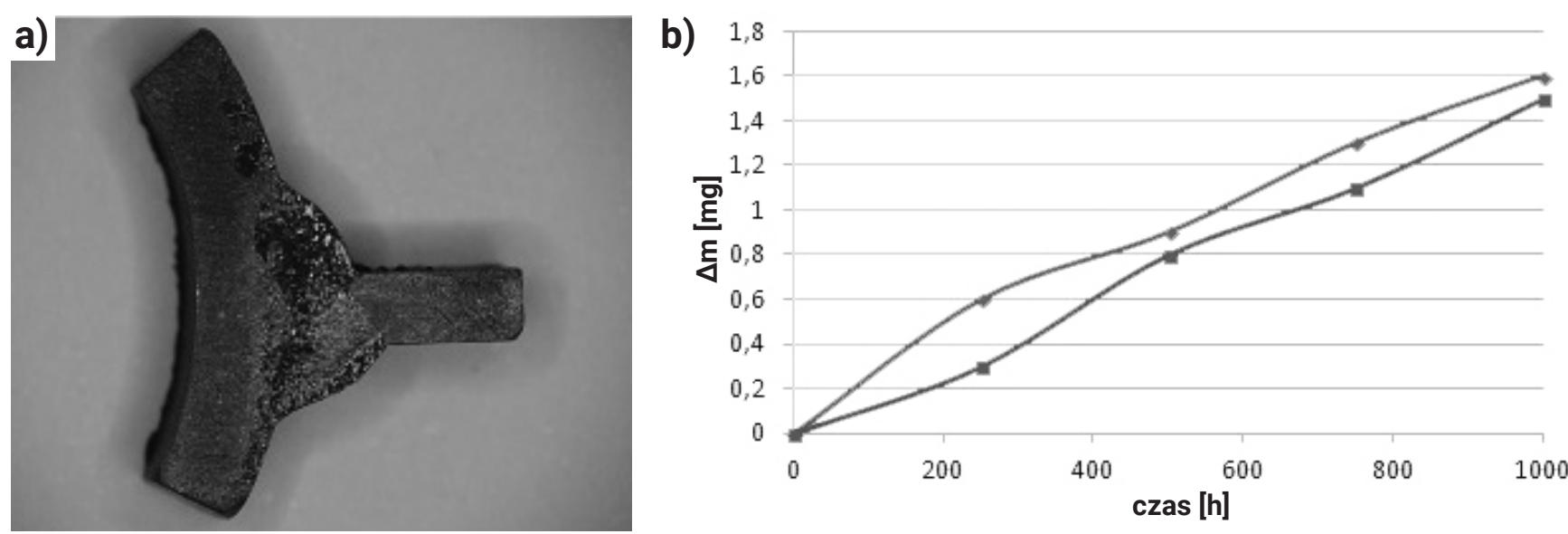

Rys. 4. Wyniki badań odporności na korozję wysokotemperaturową: a) widok próbki po badaniu, b) zmiany masy próbek w funkcji czasu Fig. 4. Test results for high temperature corrosion resistance: a) view of sample after test, $b$ ) mass changes as a function of time 

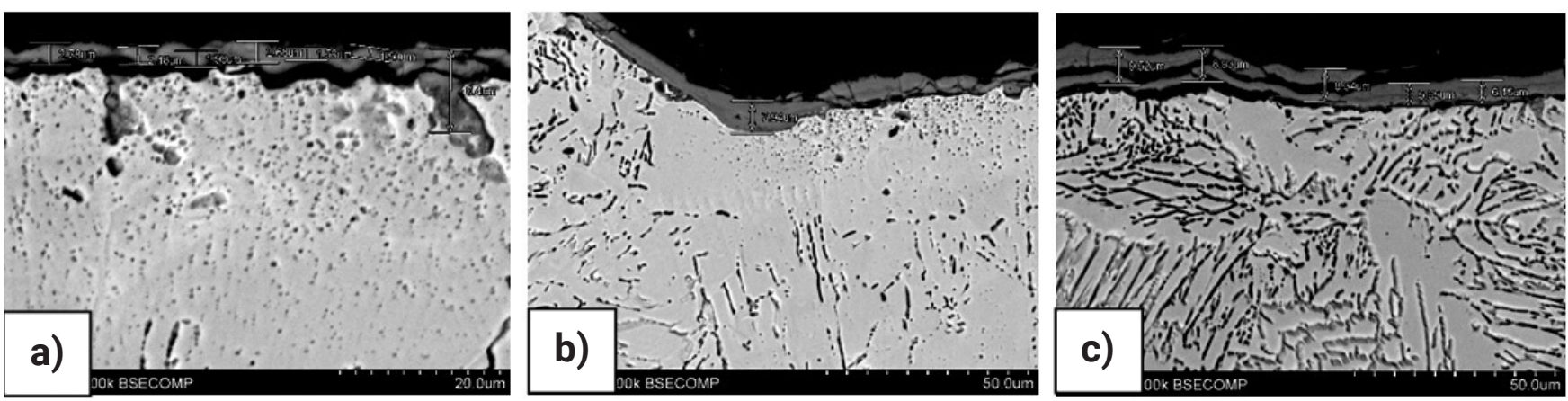

Rys. 5. Warstwa produktów korozji utworzona na powierzchni materiału w miejscu: a) materiału podstawowego, b) SWC, c) spoiny

Fig. 5. A layer of corrosion products formed on the surface of the material in place: a) basic material, b) HAZ, c) weld
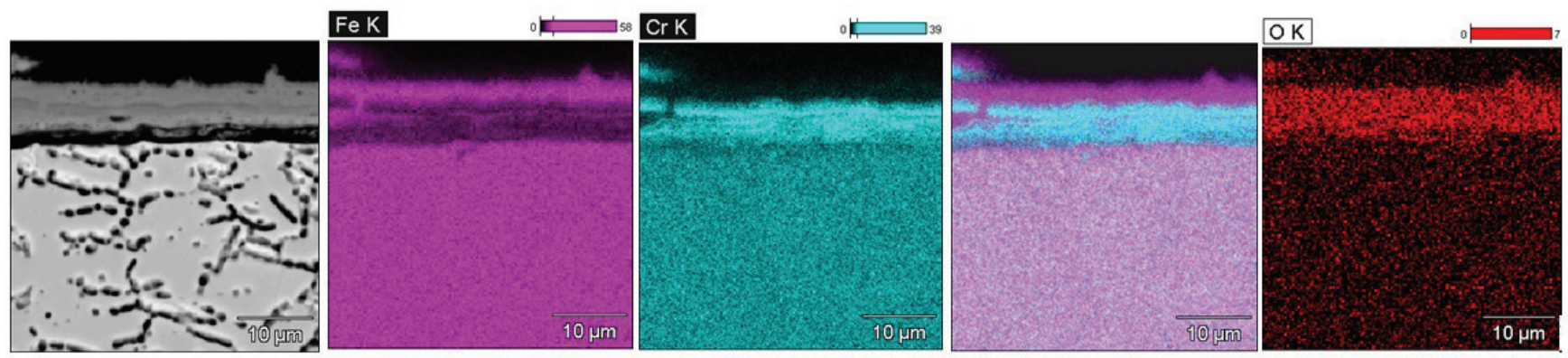

Rys. 6. Warstwa produktów korozji w obszarze spoiny i rozkłady powierzchniowe $\mathrm{Fe}, \mathrm{Cr}, \mathrm{O}$

Fig. 6. The layer of corrosion products in the weld area and surface distributions of $\mathrm{Fe}, \mathrm{Cr}, \mathrm{O}$

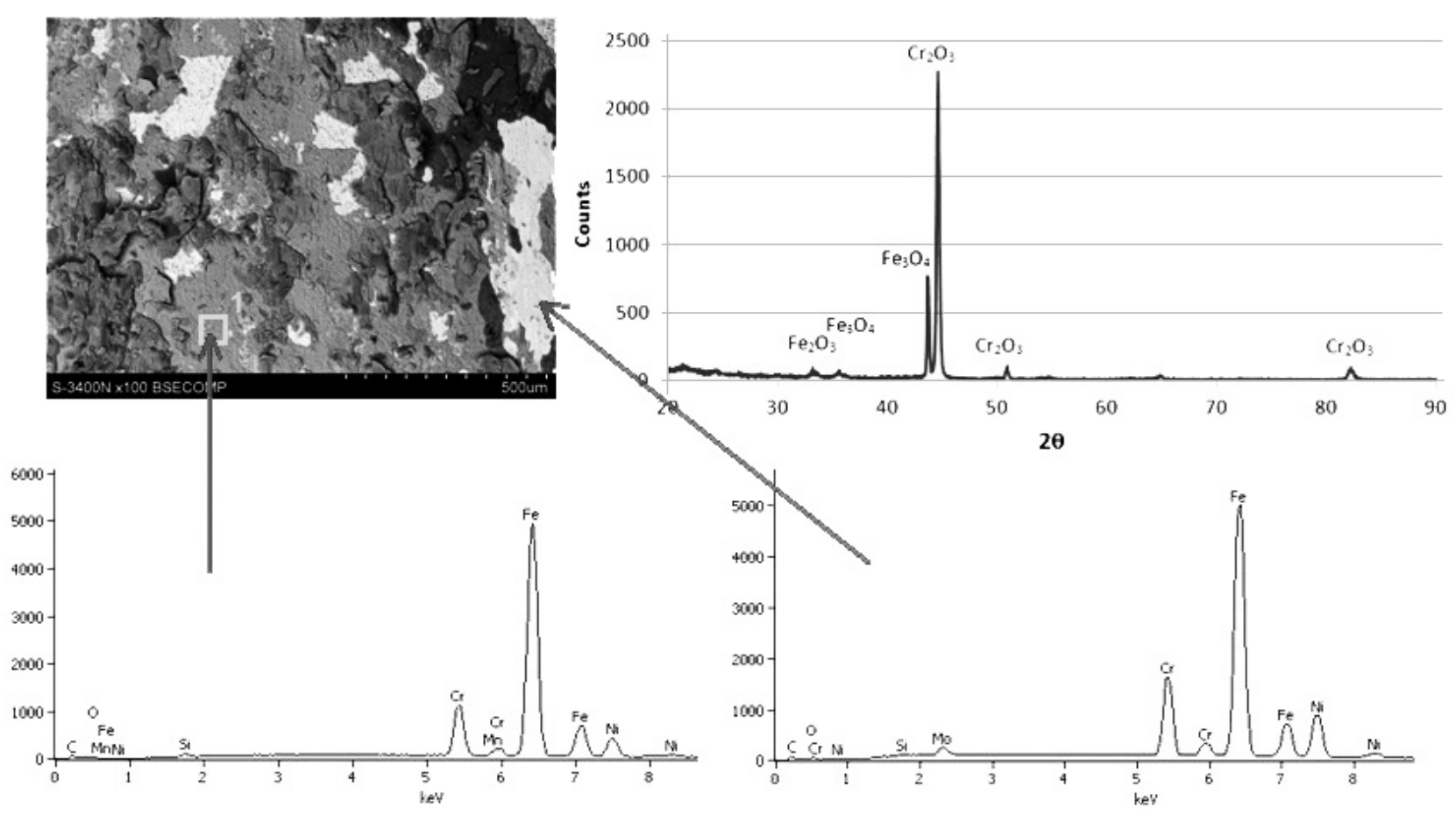

Rys. 7. Wyniki analizy składu chemicznego oraz fazowego warstwy produktów korozji

Fig. 7. Results of analysis of the chemical and phase composition of the corrosion products layer

\section{Podsumowanie}

Na podstawie wykonanych badań oraz analizy wyników stwierdzono, że złącza spawane hybrydowo laser + MAG są odporne na korozję wysokotemperaturową w atmosferze spalin w temperaturze $700{ }^{\circ} \mathrm{C}$. Obecność pasywnej warstwy $\mathrm{Cr}_{2} \mathrm{O}_{3}$ przy powierzchni materiału jest zjawiskiem korzystnym. Warstwa ta jest ciągła i przyczepna do podłoża, a w warunkach korozji wysokotemperaturowej szybko się odbudowuje. Warstwa ta może w niewielkim stopniu ograniczać wymianę ciepła pomiędzy spalinami a mieszanką parowo-wodną wewnątrz rury, ale stanowi zabezpieczenie przed dalszym utlenianiem.

\section{Literatura}

[1] Hernas A.: Trwałość i niszczenie elementów kotłów i turbin parowych, wyd. Politechniki Śląskiej, Gliwice, 2003.

[2] Formanek B., Szczucka-Lasota B.: Korozja wysokotemperaturowa stali i powłok ochronnych stosowanych w kotłach energetycznych, w: Materiały i technologie stosowane w budowie kotłów nadkrytycznych i spalarni odpadów, wyd. SITPH, Katowice, 2009.

[3] Viswanathan R., Henry J., i inni: Program on Materials Technology for USC Coal Power Plants, ECCC Creep Conf., London, 2005.

[4] Łabanowski J., Głowacka M.: Wysokotemperaturowa trwałość stali i złączy spawanych w środowisku spalin, Przegląd Spawalnictwa 5/2011, s. 2-5.
[5] Simms H.G.: Oxidation behavior of austenitic stainless steel at high temperature in supercritical plant, M. Res. thesis, University of Birmingham, 2011.

[6] Turowska A., Adamiec J.: Evaluation of high temperature corrosion resistance of finned tubes made of austenitic steel and nickel alloys, Archives of Metallurgy and Materials, Vol. 61, Iss. 2, 2016, pp. 1089-1093.

[7] Hernas A., Dobrzański J., Pasternak J., Fudali S.: Charakterystyki nowej generacji materiałów dla energetyki, wyd. Politechniki Śląskiej, Gliwice, 2015. 